\title{
Case report. Het haartourniquetsyndroom
}

\author{
Renée Hogenhout ${ }^{1}$ Marina C. Hovius ${ }^{2}$ Erich W. J. Taubert ${ }^{3}$ \\ Published online: 2 March 2018 \\ (c) The Author(s) 2018. This article is an open access publication.
}

\section{Samenvatting}

Een 48-jarige, langharige man presenteert zich met een stricturerende haarstreng onder de glans penis, wat heeft geleid tot een proximale wijde urethrafistel. Het beeld doet denken aan een amputatieproces van de glans. De haarstreng wordt verwijderd en in een later stadium volgt reconstructie van de urethra en de glans. Na literatuuronderzoek is op basis van beschikbare case reports de diagnose 'haartourniquetsyndroom' gesteld, een aandoening die louter bij kinderen is beschreven en met name de extremiteiten betreft. De gepresenteerde casus leert dat bij een progressief stricturerend proces van de glans er altijd, ongeacht de leeftijd van de patiënt, kan worden gedacht aan het haartourniquetsyndroom.

Trefwoorden haartourniquetsyndroom $\cdot$ strangulatie $\cdot$ peniel $\cdot$ urethrareconstructie

\section{Case report. Hair Tourniquet Syndrome}

\begin{abstract}
A 48 year old male patient was referred because of a circumferential constrictive process in the coronal sulcus. On examination the urologist found a hair coil inside the preputial space, surrounding the coronal sulcus with an urethral fistula proximal of the strangulation. The hair coil is removed, followed by surgical reconstruction of the urethra and the glans penis. After a review of the literature, the patient is diagnosed with 'hair tourniquet syndrome', previously only described in children. This case shows, that in a situation of a constrictive process around the penis, we have to consider the hair tourniquet syndrome as a possible diagnosis in children and in adult men.
\end{abstract}

Keywords hair tourniquet syndrome $\cdot$ strangulation $\cdot$ penile $\cdot$ urethral reconstruction

\section{Introductie}

Strangulatie van de penis door een haarstreng wordt in de literatuur betiteld als het hair tourniquet syndrome (HTS; haartourniquetsyndroom). Andere termen die dit fenomeen beschrijven, zijn onder andere progressive penile strangulation, hair coil penile strangulation en penile tourniquet syndrome. Het peniele haartourniquetsyndroom wordt lou-

Renée Hogenhout

renee.hogenhout@radboudumc.nl

1 Radboud Universitair Medisch Centrum, Nijmegen, Nederland

2 afdeling urologie, Onze Lieve Vrouwe Gasthuis, Amsterdam, Nederland

3 afdeling urologie, Slingeland Ziekenhuis, Doetinchem, Nederland ter beschreven bij kinderen en betreft hoofdzakelijk patiënten met status na circumcisie [1]. Overige, veel voorkomende lokalisaties van het haartourniquetsyndroom zijn tenen, vingers en de vrouwelijke genitalia [2]. De betreffende haar(streng) is vaak afkomstig van het hoofd van een van de ouders. De haarstreng wikkelt zich rondom de penis ter hoogte van de subcoronale groeve en veroorzaakt progressieve strangulatie. Haar van humane origine contraheert bij het opdrogen, wat leidt tot de typische insnoering [3]. In een vroeg stadium presenteren patiënten zich met peniel oedeem, eczeem, erosies en coronale fissuren. De haarstreng blijft vaak onopgemerkt doordat deze zich in een groeve van oedemateus weefsel bevindt [4]. Door uitblijven van een juiste diagnose en daarmee inadequate behandeling, ontstaat progressie van de aandoening, met als gevolg urethrafistelvorming, urethrale transsectie, gangreen en uiteindelijk amputatie van de glans. Door beschadiging 


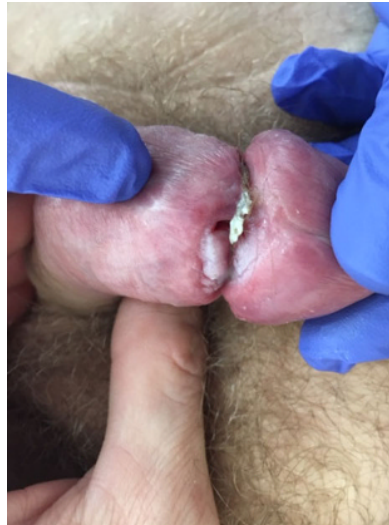

Figuur 1 Initiële presentatie: haarstreng in de subcoronale groeve

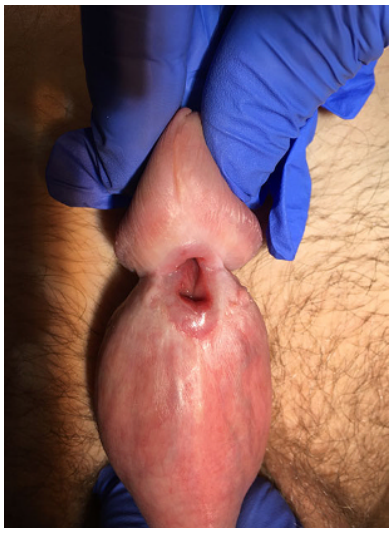

Figuur 2 Preoperatieve situatie: het corpus spongiosum en de urethra zijn over een diameter van meer dan $50 \%$ geopend

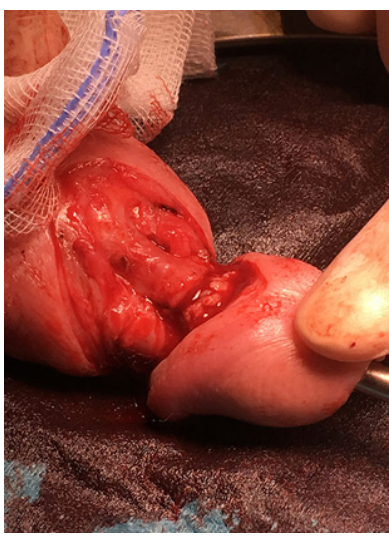

Figuur 3 Peroperatieve situatie: de urethra is gesloten. Het corpus spongiosum is nog open. De corpora cavernosa zijn in de glans vastgezet

van de neurovasculaire bundel kan het proces zich soms pijnloos voortzetten.

Wanneer de diagnose in een vroeg stadium wordt gesteld, is verwijdering van de haarstreng in de meeste gevallen afdoende voor volledig herstel. Bij gevorderde strangulatie is chirurgische reconstructie vereist.

\section{Casus}

Een 48-jarige, langharige man met een recent ontdekte diabetes mellitus type II, presenteert zich bij de huisarts met een huidafwijking onder de glans. De huisarts diagnosticeert het huidbeeld in eerste instantie als een balanopostitis en start behandeling met een antimycoticum. De klachten nemen af, maar verdwijnen niet volledig. Een aantal maanden later presenteert de patiënt zich opnieuw met een afwijking van stricturerende aard onder de glans, waar een haar uit lijkt te komen, en waarbij sprake is van urinelekkage ter plaatse. Er zijn geen klachten van hematurie, strangurie of pusafvloed uit de meatus. De patiënt denkt aan een parasitaire infectie vanwege verblijf in Suriname een aantal jaar geleden. Uit de sociale anamnese blijkt dat patiënt momenteel geen relatie heeft en niet seksueel actief is.

Bij hernieuwd lichamelijk onderzoek wordt een goed verzorgde, reële man gezien met lang blond haar. Hij heeft een normaal aangelegd genitaal en een intact preputium. Onder de glans bevindt zich beslag en een haarstreng in een diepe insnijding in de subcoronale sulcus, waardoor de glans dreigt te amputeren (fig. 1). De patiënt wordt verwezen naar de uroloog die de haarstreng verwijdert. Bij aanvullende anamnese blijkt geen sprake van automutilatie. Na verwijderen van de haarstreng wordt bij inspectie, proximaal van de insnijding, aan ventrale zijde, een voor meer dan $50 \%$ geopend(e) urethra en corpus spongiosum gezien. Subcoronaal is sprake van een circumferentiële insnoering van zowel de huid als de corpora cavernosa en is ook littekenvorming zichtbaar (fig. 2). Het beeld is niet typisch voor lichen sclerosis et atrophicus. De capillaire refill van de glans is normaal en de sensibiliteit lijkt ongestoord. Aanvullend wordt een digitaal substractieangiogram van de penis uitgevoerd. Het blijkt echter onmogelijk om de vascularisatie zo distaal in beeld te brengen.

De patiënt wordt chirurgisch behandeld middels reconstructie. De urethrale fistel wordt geaviveerd en primair gesloten (fig. 3). Vervolgens wordt de continuïteit van het corpus spongiosum hersteld. Het subcoronale weefsel wordt als circumcisie geëxcideerd en voor pathologisch onderzoek opgestuurd. Ten slotte worden de corpora cavernosa rondom op het corpus spongiosum van de glans gefixeerd, waardoor de stabiliteit van de glans is hersteld (fig. 4). Het pathologisch onderzoek van de gereseceerde subcoronale huid laat een beeld zien van chronische verlittekening die mogelijk past bij lichen sclerosis et atrophicans (LSA).

Er doen zich geen complicaties voor. Het functioneel en esthetisch resultaat is voor de patiënt zeer bevredigend.

\section{Discussie}

Na uitgebreid literatuuronderzoek is een aantal case reports gevonden over het haartourniquetsyndroom, met vergelijkbare casus. Op basis van deze bevindingen kon de diagnose worden gesteld. Retrospectief wordt de uitslag van het 


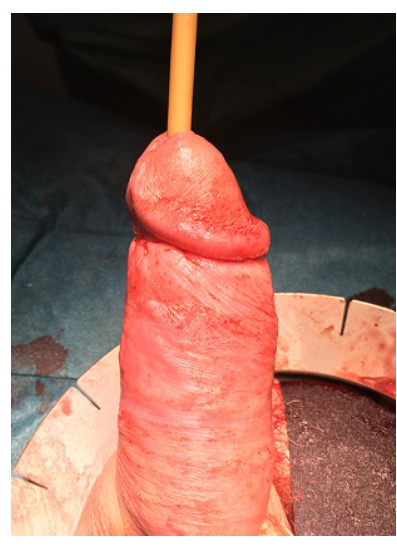

Figuur 4 Direct postoperatieve situatie: normaal aspect van de penis

pathologisch onderzoek geduid als een beeld passend bij chronische ontsteking ten gevolge van de langdurige strangulatie.

Wat deze casus uniek maakt, is het feit dat het haartourniquetsyndroom uitsluitend beschreven is bij kinderen met status na circumcisie [1]. De betreffende haarstreng is vaak afkomstig van het hoofd van een van de ouders. De patiënt in onze casus had zelf lang blond haar, dat zich om de penis onder de glans had gewikkeld. Pubisbeharing is te kort om volledige strangulatie te veroorzaken. Circumcisie is de grootste risicofactor voor het ontstaan van het haartourniquetsyndroom. Bij een besneden penis wordt de subcoronale ruimte niet meer bedekt door preputium, waardoor een haarstreng zich gemakkelijk in deze sulcus kan insnoeren.

In de huidige casus is de haarstreng, hoewel er geen sprake was van circumcisie, toch in de subcoronale groeve terechtgekomen en in eerste instantie onopgemerkt gebleven door bedekking van het preputium. De kans op het haartourniquetsyndroom bij onbesneden mannen is klein, maar geeft wel een vergroot risico op herkenning in een laat stadium. Naast circumcisie zijn postpartum haarverlies, beperkte hygiëne, kinderverwaarlozing en -mishandeling beschreven als risicofactoren [2, 5].

Unawareness en schaamtegevoelens kunnen ertoe leiden dat patiënten zich pas in een laat stadium bij de arts presenteren. De aandoening komt weinig voor, waardoor een aanzienlijke groep huisartsen het beeld niet herkent. Tevens wordt de diagnose met enige regelmaat gemist door de fijne haarstructuur. Chirurgische interventie is daardoor in veel gevallen noodzakelijk. Ook in deze casus werd de diagnose pas een jaar na het ontstaan van de eerste klachten gesteld. Onze patiënt had bovendien blond haar, dat weinig contrast vormt met de huid. Daarnaast was mogelijk sprake van enige unawareness bij de patiënt doordat hij, in de betreffende periode, geen relatie had of seksueel actief was. Ook dit kan bijgedragen hebben aan het diagnostisch delay.

De dubbele arteriële bloedvoorziening van de glans met uitgebreide anastomosering van beide corpora heeft in deze casus er schijnbaar toe bijgedragen dat de vitaliteit van de glans intact is gebleven. Hoewel er klinisch sprake leek te zijn van een intacte neurovasculariteit is, ter voorbereiding op de reconstructieve chirurgie, aanvullend een digitaal substractieangiogram uitgevoerd om de bloedvoorziening van de glans te beoordelen en het risico op verlies van vascularisatie van de glans te beperken.

\section{Conclusie}

Bij een progressief stricturerend proces van de glans moet, ongeacht de leeftijd van de patiënt, worden gedacht aan het haartourniquetsyndroom. Dankzij de dubbele vaatvoorziening van de corpora kan, zelfs in een vergevorderd stadium, een succesvolle chirurgische reconstructie worden uitgevoerd.

Open Access This article is distributed under the terms of the Creative Commons Attribution 4.0 International License (http:// creativecommons.org/licenses/by/4.0/), which permits unrestricted use, distribution, and reproduction in any medium, provided you give appropriate credit to the original author(s) and the source, provide a link to the Creative Commons license, and indicate if changes were made.

\section{Literatuur}

1. Badawy H, Soliman A, Ouf A, Hammad A, Orabi S, Hanno A. Progressive hair coil penile tourniquet syndrome: multicenter experience with 25 cases. J Pediatr Surg. 2010;45(7):1514-8.

2. Claudet I, Pasian N, Debuisson C, Salanne S, Rekhroukh H. Tourniquet syndrome: interest of a systematic analysis of families' social conditions to detect neglect situations. Child Abuse Negl. 2009;33(9):569-72.

3. Pantuck AJ, Kraus SL, Barone JG. Hair strangulation injury of the penis. Pediatr Emerg Care. 1997;13(6):423-4.

4. Dar NR, Siddiqui S, Qayyum R, Ghafoor T. Hair coil strangulation-an uncommon cause of penile edema. Pediatr Dermatol. 2007;24(4):E33-5.

5. Shohab D, Hussain I, Akhter S. Penile strangulation caused by tourniquet injury - an experience of seven cases. J Coll Physicians Surg Pak. 2014;24(8):612.

R. Hogenhout masterstudent geneeskunde

drs. M.C. Hovius uroloog

drs. E.W.J. Taubert uroloog 